\title{
Asthma in the elderly: a double-blind, placebo-controlled study of the effect of montelukast
}

\author{
Michele Columbo(i)
}

\begin{abstract}
Background: Little is known about asthma in the elderly as most studies of this condition have not included this patient group. It is unclear whether leukotriene antagonists benefit older asthmatics. We studied the effect of adding montelukast to the asthma treatment of elderly subjects.

Methods: Twenty-five subjects 65 years old and older with asthma were evaluated at week 0, 1, 5, 9, 13, and 17. Each subject received montelukast $10 \mathrm{mg}$ and placebo each for 8 weeks in a cross-over design.

Results: Montelukast for 4 or 8 weeks did not significantly affect ACT, daily symptom scores, number of puffs of albuterol, spirometric values, peripheral blood eosinophils, or serum IgE vs. baseline or placebo. Similar results were obtained when analyzing subgroups of patients with lower ACT, lower FEV1, and higher eosinophils.

Conclusions: In this study of elderly asthmatics, montelukast had no effect on asthma symptoms, number of puffs of albuterol, spirometric values, peripheral blood eosinophils or serum lgE. These results will require confirmation in larger patient cohorts and in patients with uncontrolled asthmatic symptoms.
\end{abstract}

Keywords: Asthma, Elderly, Montelukast

\section{Background}

About $13 \%$ of the U.S. population is older than 65 years of age and this percentage is expected to double by the year 2050 [1]. About 7\% of individuals 65 years old and older have asthma [1]. However, little is known about asthma in these patients as few asthma studies have examined this patient group. Older patients with asthma are more likely to be underdiagnosed, undertreated, and hospitalized when compared with younger patients affected by this condition [1]. The mortality of older asthmatics is higher than their non asthmatic counterparts [1]. The U.S. National Institute of Aging stated that asthma's pathophysiology is different in the elderly and there are many challenges in the treatments of these patients [1].

Leukotrienes are inflammatory mediators that play a significant role in the pathogenesis of asthma. In particular, leukotrienes are important in bronchoconstriction, airway edema, and mucus formation $[2,3]$.

Correspondence: michelecolumbo@msn.com

Division of Allergy and Immunology, Bryn Mawr Hospital, Bryn Mawr, PA, USA

(c) The Author(s). 2017 Open Access This article is distributed under the terms of the Creative Commons Attribution 4.0 International License (http://creativecommons.org/licenses/by/4.0/, which permits unrestricted use, distribution, and reproduction in any medium, provided you give appropriate credit to the original author(s) and the source, provide a link to the Creative Commons license, and indicate if changes were made. The Creative Commons Public Domain Dedication waiver (http://creativecommons.org/publicdomain/zero/1.0/) applies to the data made available in this article, unless otherwise stated.
They appear to decrease eosinophilic inflammation [4]. Leukotrienes are produced by mast cells, basophils, eosinophils, and other cells [3].

Montelukast (Singulair ${ }^{\circ}$ ) is a leukotriene receptor antagonist US FDA approved for the treatment of asthma in subjects who are 12 months old and older. Its benefits include improved asthma symptoms and spirometric values, and decrease of asthma exacerbations compared to placebo [5]. In general, leukotriene inhibitors are considered less effective than inhaled corticosteroids [6], but they may be beneficial when added to these drugs [7].

There is little information regarding the effect of leukotriene antagonists in elderly asthmatics. Two studies of zafirlukast suggested that this leukotriene antagonist may be less effective in older patients $[8,9]$. Two open label studies in subjects older than 60 years old showed that treatment with montelukast may provide clinical benefit when added to inhaled corticosteroids $[10,11]$.

The main purpose of this pilot study is to investigate the effect of adding montelukast to elderly asthmatics' treatment regimen on asthma symptoms assessed by the 
Asthma Control Test (ACT) (primary objective), daily symptom scores, number of puffs of albuterol, and spirometric values. This is a randomized, double-blind, placebo controlled, cross-over study.

Secondary objectives of this study include investigating whether montelukast in elderly asthmatics affects the number of peripheral blood eosinophils and serum IgE levels.

\section{Methods}

This study included six study visits at week $0,1,5,9,13$, and 17. After a one week run-in period, the study subjects were given montelukast and placebo in a crossover design. They took montelukast $10 \mathrm{mg}$ and placebo each for 8 weeks. Compliance with the study drugs, based on the returned study bottles and with the daily symptom diaries was very good $(>90 \%)$.

Twenty-five subjects 65 years old and older with asthma completed this study. Twenty-four were Caucasian and 1 African-American. One additional subject discontinued his participation within the first few weeks for reasons unrelated to the study. Allergic sensitization was verified by allergy skin tests for relevant allergens. Current smokers and subjects with $>10$ pack/year history of smoking were excluded from this study. Almost all of the study subjects were lifetime nonsmokers. Subjects with recent $(<4$ weeks before randomization) asthma exacerbation or treatment with systemic steroids, and history of hypereosinophilic disorders were also excluded. Treatment with montelukast or other leukotriene antagonist was not allowed for at least 4 weeks prior to randomization. Study participants were instructed to continue their regular asthma treatment, if any, without any change during the study period unless required by an asthma exacerbation. The study subjects were recruited among interested and eligible patients with asthma followed in a suburban Allergy and Immunology practice.

Spirometric values were obtained according to the ATS/ARS guidelines by a KoKo Spirometer (nSpire Health Inc., Longmont, CO). The ACT is a tool that allows patients to report asthmatic symptoms on a scale from 1 (severe) to 5 (no symptoms) by answering questions about asthma control in the previous 4 weeks. For the duration of the study, each subject filled a daily diary grading their asthma symptoms on a scale from 0 (no symptoms) to 5 (very severe symptoms). The number of puffs of albuterol was also reported daily. Peripheral blood eosinophils were enumerated and total serum IgE measured at the MLH Laboratories at weeks 9 and 17. The inhaled steroids used by the study subjects were fluticasone (14), budesonide (4), mometasone (3), and beclomethasone (1). Inhaled steroid doses are expressed as fluticasone equivalent. Long acting bronchodilators were salmeterol (12), formoterol (5), and vilanterol (1).
Data are expressed as the mean \pm standard deviation and analyzed by the two tailed, paired $t$ test with significance accepted at $<0.05$. The number of 25 subjects was calculated as previously reported [12]. In particular, the goal was set to see a 10\% improvement (effect size) of the ACT score following the treatment with montelukast vs. placebo. In our earlier study of exhaled nitric oxide measurements in elderly asthmatics [13], the mean ACT score was 22.2 and the standard deviation was $2.8 \%(n=$ $30)$. The calculated standardized effect size is $10 \%$ of $22.2(2.2) / 2.8=0.8$. Therefore, $\beta=0.2(1 / 0.8)$. For an $\alpha$ of 0.05 (two tailed $t$ test) the number necessary to see a $10 \%$ change is 25 .

This study was registered on clinicaltrials.gov (NCT02635334).

\section{Results}

Table 1 summarizes the baseline characteristics of the study subjects. Most subjects were atopic (80\%), on inhaled steroids (88\%) and long acting bronchodilators (72\%), and had well controlled asthma.

Montelukast for 4 or 8 weeks had no effect on ACT (Table 2). At 8 weeks, daily symptom scores and number of puffs of albuterol per week seem decreased by montelukast when compared to placebo (Table 2). However, neither of such decreases was statistically significant. Montelukast exerted no effect on ACT, daily symptom

Table 1 Subjects' characteristics at baseline

\begin{tabular}{ll}
\hline Age (years, range) & $72.9 \pm 4.9,66-82$ \\
Sex (F/M) & $16 / 9$ \\
BMl & $26.7 \pm 5.6$ \\
Atopy & $20 / 25$ \\
Duration of asthma (years) & $35.7 \pm 24.8$ \\
Rhinitis & $18 / 25$ \\
Gastroesophageal reflux disease & $9 / 25$ \\
Inhaled steroids (dose, range) & $22 / 25(388 \pm 324,0-1,000$ mcg/day) \\
Long -acting bronchodilators & $18 / 25$ \\
Anti-cholinergic agents & $5 / 25$ \\
(tiotropium) & $1 / 25$ \\
Theophylline & $22.9 \pm 2.1$ \\
ACT score & $0.3 \pm 0.6$ \\
Daily asthma symptom score & $0.8 \pm 1.8$ \\
Number of puffs of albuterol per & \\
week & $81.2 \pm 15.8$ \\
FEV1\% & $0.74 \pm 0.1$ \\
FEV1/FVC & $78.2 \pm 31.5$ \\
FEF25-75\% & $0.38 \pm 0.25$ \\
Peripheral blood eosinophils (K/ $\mu \mathrm{L})$ & $182 \pm 249$ \\
Total serum lgE (IU/ml) & \\
\hline N 25 &
\end{tabular}
$N=25$ 
Table 2 Effect of montelukast on ACT, daily symptom scores, and number of puffs of albuterol/week

\begin{tabular}{lccc}
\hline & Baseline & 4 weeks & 8 weeks \\
\hline ACT (montelukast) & $22.9 \pm 2.1$ & $22.8 \pm 2.8$ & $23 \pm 3.2$ \\
ACT (placebo) & & $23.4 \pm 2.1$ & $22.3 \pm 4.4$ \\
Daily symptom score (montelukast) & $0.3 \pm 0.6$ & $0.3 \pm 0.5$ & $0.3 \pm 0.6$ \\
Daily symptom score (placebo) & & $0.3 \pm 0.5$ & $0.5 \pm 0.7$ \\
Puffs of albuterol/week (montelukast) & $0.8 \pm 1.8$ & $1.2 \pm 3$ & $0.7 \pm 1.7$ \\
Puffs of albuterol/week (placebo) & & $0.7 \pm 1.5$ & $1.5 \pm 3.7$ \\
\hline $\begin{array}{l}N=25 \\
p>0.3 \text { vs. placebo for ACT; } p=0.06 \text { for daily symptom score vs. placebo at }\end{array}$ \\
$\begin{array}{l}\text { 8 weeks; } p=0.44 \text { for puffs of albuterol vs. placebo at } 4 \text { weeks; } p=0.11 \text { for } \\
\text { puffs of albuterol vs. placebo at } 8 \text { weeks }\end{array}$
\end{tabular}

scores, or puffs of albuterol/week when compared to baseline values ( $p>0.54$ for all comparisons).

Montelukast for 4 or 8 weeks did not affect spirometric values when compared to placebo (Table 3 ). However, The FEV1 values obtained at 4 and 8 weeks for both montelukast and placebo were reduced when compared to baseline $(p<0.026$ and $p<0.052$ for montelukast and $<0.001$ and $p<0.002$ for placebo, respectively).

Montelukast for 8 weeks had no effect on peripheral blood eosinophils or serum IgE compared to placebo (Table 4 ) or baseline values ( $p>0.34$ for all comparisons).

Post-hoc analysis showed that in non atopic subjects, subjects with lower baseline ACT scores $(\leq 21)$, higher serum IgE (>200 IU/ml), or lower FEV1\% (<60\%), montelukast did not have a significant effect vs. placebo (Table 5).

In subjects with higher baseline peripheral blood eosinophil counts $(\geq 0.6 \mathrm{~K} / \mu \mathrm{L})$, montelukast for 8 weeks appeared to reduce such counts vs. placebo (Table 5), but its effect did not reach statistical significance. In these subjects, asthma symptoms and spirometric values were unaffected by montelukast (data not shown).

\section{Discussion}

In this pilot study, we evaluated the effect of adding montelukast to the treatment of elderly subjects with asthma. This group of patients has been mostly ignored in previous studies of this condition.

Table 3 Effect of montelukast on spirometric values

\begin{tabular}{llll}
\hline & Baseline & 4 weeks & 8 weeks \\
\hline FEV1\% (montelukast) & $81.2 \pm 15.8$ & $77.5 \pm 16.1$ & $77.3 \pm 17.7$ \\
FEV1\% (placebo) & & $76.6 \pm 16.4$ & $75.2 \pm 17$ \\
FEV1/FVC (montelukast) & $0.74 \pm 0.1$ & $0.75 \pm 0.1$ & $0.74 \pm 0.1$ \\
FEV1/FVC (placebo) & & $0.74 \pm 0.1$ & $0.74 \pm 0.1$ \\
FEF25-75\% (montelukast) & $78.2 \pm 31.5$ & $75.5 \pm 32.2$ & $75.4 \pm 35$ \\
FEF25-75\% (placebo) & & $72.7 \pm 29$ & $73.1 \pm 30.8$ \\
\hline$N=25$ & & \\
$p>0.35$ vs. placebo for all comparisons & &
\end{tabular}

Table 4 Effect of montelukast on peripheral blood eosinophils $(\mathrm{K} / \mu \mathrm{L})$ and total serum $\lg \mathrm{E}(\mathrm{IU} / \mathrm{ml})$

\begin{tabular}{lll}
\hline & Baseline & 8 weeks \\
\hline Eosinophils (montelukast) & $0.38 \pm 0.25$ & $0.37 \pm 0.32$ \\
Eosinophils (placebo) & & $0.45 \pm 0.42$ \\
$\lg E$ (montelukast) & $182 \pm 249 \pm 272$ \\
$\lg$ (placebo) & & $218 \pm 358$ \\
\hline$N=25$ & \\
$p>0.34$ vs. placebo for all comparisons &
\end{tabular}

Two open label studies in asthmatic subjects 60 years old and older showed clinical benefits from adding montelukast to inhaled corticosteroids with or without long acting bronchodilators $[10,11]$. Such benefits included a reduction of asthma exacerbations $[10,11]$, reduction of the percentage of days with asthma and short betareceptor agonist [10]. In the present study, adding montelukast for 4 and 8 weeks to our subjects' treatment had no effect on ACT or spirometric values. Montelukast for 8 weeks appeared to reduce daily symptoms scores and number of puffs of albuterol vs. placebo, but such results did not reach statistical significance, possibly due to the low baseline values. Indeed, a significant limitation of our results is that most study subjects had well controlled asthma. The lack of effect of montelukast on clinical parameters could have been the result of this limitation.

A previous study showed that montelukast decreases peripheral blood eosinophils [6]. Another study failed to detect an effect of montelukast on sputum eosinophils when added to inhaled corticosteroids [11]. In the present study of elderly asthmatics, montelukast did not affect peripheral blood eosinophils or serum IgE levels. Montelukast appeared to decrease eosinophils in subjects with higher baseline blood counts of these cells, but these results did not reach statistical significance possibly due to the small number of observations. Although no clinical

Table 5 Effect of montelukast in different subjects' subgroups

\begin{tabular}{|c|c|c|c|}
\hline & Baseline & 4 weeks & 8 weeks \\
\hline ACT nonatopic (montelukast) & $22.2 \pm 1.8$ & $20.8 \pm 4.6$ & $23.6 \pm 2.1$ \\
\hline ACT nonatopic (placebo) & & $23.8 \pm 0.8$ & $20.4 \pm 6$ \\
\hline ACT $\leq 21$ (montelukast) & $20.2 \pm 1.8$ & $22 \pm 2$ & $21.2 \pm 6.4$ \\
\hline$A C T \leq 21$ (placebo) & & $21.8 \pm 3.3$ & $19.8 \pm 7.1$ \\
\hline ACT IgE > $200 \mathrm{IU} / \mathrm{ml}$ (montelukast) & $22.6 \pm 2.7$ & $23.5 \pm 1.7$ & $22 \pm 5$ \\
\hline ACT IgE > $200 \mathrm{IU} / \mathrm{ml}$ (placebo) & & $23 \pm 3$ & $22 \pm 5.4$ \\
\hline FEV1\% < 60\% (montelukast) & $54.5 \pm 5.4$ & $50.8 \pm 9.5$ & $52.2 \pm 6.3$ \\
\hline FEV1\% < 60\% (placebo) & & $50.3 \pm 4.9$ & $51.8 \pm 6.4$ \\
\hline Eosinophils $\geq 0.6 \mathrm{~K} / \mu \mathrm{L}$ (montelukast) & $0.83 \pm 0.22$ & & $0.54 \pm 0.11$ \\
\hline Eosinophils $\geq 0.6 \mathrm{~K} / \mu \mathrm{L}$ (placebo) & & & $1.22 \pm 0.5$ \\
\hline $\begin{array}{l}N=8 \text { for } \mathrm{ACT} \operatorname{lgE}>200 \mathrm{IU} / \mathrm{ml} ; n=5 \text { for } \mathrm{A} \\
\mathrm{FEV} 1 \%<60 \% \text { and eosinophils } \geq 0.6 \mathrm{~K} / \mu \mathrm{L}) \\
p=0.07 \text { vs. placebo for eosinophils }>0.6 \\
\text { other comparisons }\end{array}$ & T & and $\mathrm{ACT} \leq 2$ & $1 ; n=4$ for \\
\hline
\end{tabular}


benefit of montelukast in these subjects was observed, it can be hypothesized that this subgroup of patients may be more responsive to this drug.

Additional limitations of this study include the relatively small number of subjects who were almost exclusively Caucasian. It is possible that a longer duration of treatment might have yielded different results. It is also possible that montelukast may have a positive effect on other important clinical parameters such as asthma exacerbations and asthma related emergency room visits that could not be assessed in our study.

\section{Conclusions}

In summary, in this study of stable elderly asthmatics, adding montelukast had no effect on asthma symptoms, use of albuterol, spirometric values, or peripheral blood eosinophils. These results will require confirmation in larger studies enrolling subjects with uncontrolled asthma.

\section{Abbreviations}

ACT: Asthma control test; BMI: Body mass index

\section{Acknowledgements}

The author thanks Albert S. Rohr, M.D. for enrolling some of the study subjects and conducting many study visits, Jack Korbutov, Pharm.D. for preparing the study placebo, and Kelley Mowatt, M.S. for her assistance with the study blinding and randomization.

\section{Funding}

This study was supported by the Sharpe-Strumia Research Foundation of The Bryn Mawr Hospital (SSRF2015-01). This foundation played no role in the design of the study, in the collection, analysis, and interpretation of the data or in writing the manuscript.

\section{Availability of data and materials}

All data generated or analyzed during this study are included in the published article.

\section{Author's contribution}

The author designed this study, secured its funding and IRB approval, prepared the study source documents and subjects' diaries, recruited most of the study subjects and conducted most of the study visits, collected and analyzed the study results, and prepared this manuscript.

\section{Author's information}

Dr. Columbo graduated from the University of Naples Federico II School of Medicine, Italy, in 1983. At the same institution, he was later an Assistant Professor (tenure) in the Department of Medicine for more than eight years. While in Italy, he became a certified specialist in Allergy and Clinical Immunology and in Rheumatology. In the U.S., he attended a Residency program in Internal Medicine at the Greater Baltimore Medical Center, became board certified in this specialty, and recertified in 2009. He spent more than six years in the Allergy and Clinical Immunology Division of the Johns Hopkins University School of Medicine. There he performed research as a Research Fellow and Visiting Assistant Professor and returned to complete his Clinical Fellowship. He is board certified in Allergy and Immunology and recertified in 2011. He has been in a private Allergy and Immunology practice in Bryn Mawr, Pennsylvania, U.S.A. since 2000. He is a Fellow of the American Academy of Allergy, Asthma and Immunology and the American College of Allergy, Asthma and Immunology. He has co-authored 104 publications (including 46 abstracts) mainly focused on the mechanisms of allergy. Such publications include research articles in the Journal of Immunology, Journal of Allergy and Clinical Immunology, Journal of Pharmacology and Experimental Therapeutics, American Review of Respiratory Diseases, and Blood. He has been a speaker at international conferences and received numerous research grants and awards. In the past nine years, he has initiated six clinical research projects (including the current study) that received financial support from a local non-profit foundation and were registered on clinicaltrials.gov. The five earlier studies were published in peer reviewed journals. He is a reviewer for several medical journals. He is a past President of the Philadelphia Allergy Society, a member of the Main Line Hospitals Institutional Review Board (since 2008) and the Scientific Committee of the Sharpe-Strumia Research Foundation (since 2012).

\section{Competing interests}

The author declares that he has no competing interests.

\section{Consent for publication}

Not applicable.

\section{Ethics approval and consent to participate}

This study was approved by the Main Line Hospitals Institutional Review Board and all study subjects signed an informed consent form prior to their enrollment.

\section{Publisher's Note}

Springer Nature remains neutral with regard to jurisdictional claims in published maps and institutional affiliations.

Received: 24 February 2017 Accepted: 6 April 2017

Published online: 17 April 2017

\section{References}

1. Hanania NA, King MS, Braman SS, Saltoun C, Wise RA, Enright P, et al. Asthma in the elderly: current understanding and future research needs - a report of a National Institute on Aging (NIA) workshop. J Allergy Clin Immunol. 2011;128(Suppl):4-24.

2. Adelroth E, Morris MM, Hargreave FE, O'Byrne PM. Airway responsiveness to leukotriene C4 and D4 and to methacholine in patients with asthma and normal controls. N Engl J Med. 1986;315:480-4.

3. Wenzel SE. Antileukotriene therapy in asthma. In: Middleton's allergy. Principles and practice. Seventhth ed. Maryland Heights: Mosby Elsevier; 2009. p. 1619-32.

4. Mulder A, Gauvreau GM, Watson RM, O'Byrne PM. Effect of inhaled leukotriene D4 on airway eosinophilia and airway hyperresponsiveness in asthmatic subjects. Am J Respir Crit Care Med. 1999;159:1562-7.

5. Reiss TF, Chervinsky P, Dockhorn RJ, Shingo S, Seidenberg B, Edwards TB. Montelukast, a once-daily leukotriene receptor antagonist, in the treatment of chronic asthma. Arch Intern Med. 1998;158:1213-20.

6. Malmstrom K, Rodriguez-Gomez G, Guerra J, Villaran Piñeiro A, Wei LX, Seidenberg BC, et al. Oral montelukast, inhaled beclomethasone, and placebo for chronic asthma. Ann Intern Med. 1999;130:487-95.

7. Laviolette M, Malmstrom K, Lu S, Chervinsky P, Pujet JC, Peszek I, et al. Montelukast added to inhaled beclomethasone in treatment of asthma. Montelukast/Beclomethasone additivity group. Am J Respir Crit Care Med. 1999:160:1862-8.

8. Korenblatt PE, Kemp JP, Scherger JE, Minkwitz MC, Mezzanotte W. Effect of age on response to zafirlukast in patients with asthma in the Accolate clinical experience and pharmacoepidemiology trial (ACCEPT). Ann Allergy Asthma Immunol. 2000;84:217-25.

9. Creticos P, Knobil K, Edwards LD, Rickard KA, Dorinsky P. Loss of response to treatment with leukotriene receptor antagonists but not inhaled corticosteroids in patients over 50 years of age. Ann Allergy Asthma Immunol. 2002;88:401-9.

10. Bozek A, Warcocka-Szoltysek B, Filipowska-Gronska A, Jarzab J. Montelukast as a add-on therapy to inhaled corticosteroids in the treatment of severe asthma in elderly patients. J Asthma. 2012;49:530-4.

11. Ye Y-M, Kim S-H, Hur G-Y, Kim J-H, Park J-W, Shim JJ, et al. Addition of montelukast to low-dose inhaled corticosteroid leads to fewer exacerbations in older patients than medium-dose inhaled corticosteroid monotherapy. Allergy, Asthma Immunol Res. 2015;7:440-6.

12. Columbo M, Rohr AS. Asthma in the elderly: the effect of choline supplementation. Allergy, Asthma Clin Immunol. 2016;12:15.

13. Columbo M, Wong B, Panettieri Jr RA, Rohr AS. Asthma in the elderly: the role of exhaled nitric oxide measurements. Respir Med. 2013;107:785-7. 